\title{
A percepção das puérperas sobre a humanização da assistência ao parto em um hospital do Vale do Paranhana/RS.
}

\section{The perception of postpartum women on the humanization of childbirth care in a hospital in Vale do Paranhana/RS}

\author{
Valquíria Lucinéia dos Santos Sperb ${ }^{1 *}$, Thiago da Silva ${ }^{2}$, Alexander Quadros ${ }^{2} J u l i a$ Cruz Alvez ${ }^{2}$ \\ Amaranta Rangel Ramos², Monique Perreira Guedes2
}

\begin{abstract}
RESUMO
Objetivou-se identificar a percepção, as expectativas e o conhecimento das puérperas em relação à experiência do parto e em relação ao contato pele a pele com o seu bebê no momento imediato do nascimento. Trata-se de pesquisa qualitativa exploratório-descritiva, realizada com treze puérperas em um hospital da região noroeste do Estado do Rio Grande do Sul, no período de setembro a outubro de 2017. Utilizou-se entrevista semiestruturada como técnica de coleta dados os quais foram analisados mediante análise do tipo temática. Emergiram as seguintes categorias: percepções, expectativas e conhecimentos sobre o parto humanizado; contato precoce pele a pele entre mãe e filho; comunicação como componente do cuidado durante o parto. $\mathrm{O}$ suporte contínuo durante o trabalho de parto tem benefícios clinicamente significativos para mulheres e bebês, sendo um direito legislado onde todas as mulheres devem ter apoio a ser garantido pelos serviços de saúde.
\end{abstract}

Palavras-chave: Puérperas; Alojamento Conjunto; Amamentação;

\section{ABSTRACT}

The objective was to identify the perception, expectations and knowledge of postpartum women in relation to the experience of childbirth and in relation to skin-to-skin contact with their baby immediately after birth. This is an exploratory-descriptive qualitative research, carried out with thirteen mothers in a hospital in the northwest region of the State of Rio Grande do Sul, from September to October 2017. A semi-structured interview was used as a data collection technique analyzed through thematic analysis. The following categories emerged: perceptions, expectations and knowledge about humanized childbirth; early skin-toskin contact between mother and child; communication as a component of care during childbirth. Ongoing support during labor has clinically significant benefits for women and babies, being a lawful right where all women must have support to be guaranteed by health services.

Keywords: Postpartum women; Joint accommodation; Breast-feeding;

\footnotetext{
${ }^{1}$ Secretária de Saúde Rolante/Rs. *valquiriasperb@gamil.com

${ }^{2}$ Faculdade Meridional - IMED
} 


\section{INTRODUÇÃO}

$\mathrm{O}$ parto humanizado compreende o atendimento individualizado, centrado na mulher e fundamentado na enfermagem baseada em evidências. A humanização do parto foi implantada por meio do Programa de Humanização no Pré-natal e Nascimento (PHPN), instituído pela portaria $n^{\circ} 569$, de 01/06/2000, do Ministério da Saúde. Este movimento pela humanização acontece para incentivar o parto vaginal, o aleitamento materno no pós-parto imediato e a presença do acompanhante no processo do parto (PINHEIRO, 2012).

O ideal é que, na primeira hora após o parto, se tenha o contato pele a pele, favorecendo a interação entre mãe-bebê. Neste período, o profissional de saúde deve favorecer ao máximo o contato íntimo, evitando procedimentos desnecessários ou que possam ser realizados mais tarde. $\mathrm{O}$ afastamento mãe-bebê e a sedação da mãe, privam o binômio deste momento tão especial (BRASIL, 2012).

Nesse sentido, o cuidado satisfatório é aquele desenvolvido com simpatia, educação, respeito e conhecimentos, constatando, assim, a importância das relações interpessoais e do acolhimento nos serviços de saúde. Estas relações podem viabilizar uma rede de conversações, que é essencial ao cuidado na medida em que contribui com o estabelecimento de negociações entre as necessidades dos usuários e os meios de satisfazê-las (RODRIGUES et al., 2014).

É no âmbito hospitalar que a mulher vivenciará uma experiência prazerosa ou traumática e cabe aos profissionais de saúde apoiar a gestante neste momento, tranquilizando-a e permitindo que a mesma verbalize seus medos. As orientações na sala de parto são importantes para acalmar, tranquilizar e estimular no processo da "força" para a passagem do bebê (PINHEIRO, 2012). As rotinas hospitalares, muitas vezes, impossibilitam que a parturiente decida sobre as condutas a serem realizadas durante o parto, deixando de ser a personagem principal deste processo. A humanização vem almejando a autonomia da mulher durante o parto, respeitando seus valores e hábitos, onde a equipe de saúde tem papel fundamental na implementação do parto humanizado (GONÇALVES, 2016). 
No Alojamento Conjunto (AC), as puérperas precisam ser estimuladas a realizar o autocuidado e proporcionar os devidos cuidados a seus filhos. O papel do profissional de enfermagem neste sistema está focado na educação e orientação à saúde para que as puérperas adquiram segurança e tranquilidade ao assumir seu papel de mãe por meio de estratégias de enfrentamento e adaptação ao ambiente hospitalar, para que a gestante se sinta acolhida diante da equipe que irá acompanhar antes, durante e depois do processo do parto (MARQUES et al., 2014). O cuidado de enfermagem no puerpério integra um conjunto de ações subdivididas em três períodos, que chamamos de: imediato $\left(1^{\circ}\right.$ a 10 dias de vida), tardio (11 a 45 dias de vida), e remoto (a partir dos 45 dias de vida). São períodos que requerem atenção, cuidado diferenciado, tanto da equipe de saúde, familiares, quanto da própria mulher (ANDRADE et al., 2015).

Nas pesquisas sobre a humanização do parto, nota-se que esta temática é bastante abordada na literatura, porém, ainda pouco explorada. Esta é a percepção das puérperas frente à humanização da assistência e o vínculo mãe-bebê após o parto. Os objetivos do presente trabalho, portanto, são conhecer a percepção, as expectativas e o conhecimento das puérperas em relação à experiência do parto, assim como os procedimentos utilizados pelos profissionais da saúde para a humanização do parto, além de identificar a experiência de mulheres em relação ao contato pele a pele com o seu bebê no momento imediato ao nascimento e a aproximação entre a mulher e os profissionais da saúde, para esclarecimento de suas dúvidas e anseios no que diz respeito aos aspectos do puerpério, garantindo uma atenção integral.

\section{METODOLOGIA}

Trata-se de um estudo com abordagem qualitativa do tipo exploratório-descritivo. As pesquisas qualitativas não definem todos os conceitos os quais mostram interesse, mas procuram estabelecer os significados a partir do que está sendo estudado, possibilitando a descoberta de novos conceitos e/ou possibilidades (CRESWELL e CLARK 2013; LACERDA e COSTENARO, 2016). A investigação foi desenvolvida na Maternidade Alojamento Conjunto (AC) de um hospital de grande porte da cidade de Parobé/RS. Os sujeitos selecionados foram 13 puérperas que atenderam aos seguintes critérios de inclusão: estarem internadas no alojamento conjunto no período puerperal, ter idade 
superior a 18 anos e concordância em participar da pesquisa com assinatura do Termo de Consentimento Livre e Esclarecimento (TCLE).

A coleta das informações se deu por meio de uma entrevista semiestruturada, que permite ao pesquisador elaborar um roteiro com uma série de questões a serem exploradas com os entrevistados, possibilitando uma maior profundidade e interação entre ambos (TRIVIÑOS, 2007), sendo elaboradas quatro questões abertas: (1) sobre o acolhimento e a permanência de um acompanhante na hora do nascimento de seu filho; (2) vínculo mãe/bebê e contato pele a pele; (3) compreensão da enfermagem sobre o parto humanizado na atenção básica durante o atendimento, aspectos negativos e positivos que possam contribuir para melhorias em relação ao parto humanizado. O processo de coleta de dados iniciou-se após o conhecimento das rotinas estabelecidas pela instituição e a apresentação dos pesquisadores aos sujeitos da pesquisa. As entrevistas foram previamente combinadas com os sujeitos, sendo realizadas em uma sala reservada e gravadas em áudio, tendo duração média de 30 minutos.

A escolha dos sujeitos deu-se por conveniência e com o critério de saturação das informações, o qual permite uma flexibilidade quanto ao número de informantes. A partir da $12^{\mathrm{a}}$ entrevista, observou-se que as informações começaram a apresentar um mesmo conteúdo e decidiu-se concluir com 13 participantes. Para a análise das informações, utilizou-se a técnica de análise de conteúdo do tipo temática (MINAYO, 2000). Os participantes foram codificados pela letra $\mathrm{P}$, acrescida de um algarismo numérico. Os fragmentos extraídos das falas dos participantes foram representados em unidades de significado (US), seguidas de algarismos numéricos.

As questões éticas foram respeitadas e empregadas de acordo com as Diretrizes e Normas Regulamentadoras de Pesquisa em Seres Humanos, conforme a resolução no 466/2012 do Conselho Nacional de Saúde. A pesquisa foi aprovada pelo Comitê de Ética em Pesquisa (CEP) da Fundação Educacional Encosta Inferior do Nordeste - Faculdades Integradas de Taquara/RS (FACCAT), sendo aprovada sob protocolo $n^{\circ}$ CAAE 73411817.4.0000.8135. Todos os participantes assinaram um Termo de Consentimento Livre e Esclarecido (TCLE).

RESULTADOS E DISCUSSÃO

Caracterização dos sujeitos 
Foram entrevistadas 13 puérperas, na faixa etária entre 17 e 37 anos. Em relação ao estado civil, $38,5 \%$ da amostra são solteiras, entretanto, convivem com companheiros em união estável. As outras puérperas são casadas legalmente. A distribuição conforme a ocupação ou profissão apresentou $15 \%$ sendo mulheres “do lar". O restante delas $(85 \%)$ tinha alguma ocupação ou profissão remunerada. Considerando as semanas de gestação em que se encontravam as participantes, o número de consultas realizadas está dentro dos parâmetros recomendados, tendo em vista que $31 \%$ delas realizaram de 5 a 6 consultas, e 69\% já haviam consultado mais de 7 vezes. Diante dos achados, observa-se, pelo número de consultas, que foi garantido um atendimento periódico e contínuo.

Durante as consultas de pré-natal, $31 \%$ relataram ter realizado acompanhamento com o profissional médico e enfermeiro, sendo $69 \%$ somente com o profissional médico. Um aspecto importante destacado pelas entrevistadas, foi que quando a consulta era realizada pelo enfermeiro, elas se sentiam acolhidas por meio de uma escuta respeitosa e comprometida em sanar suas dúvidas e anseios da hora do parto, sobretudo no que diz respeito à amamentação e aos primeiros cuidados com o recém-nascido. Pelo Decreto 94.406/87, lei 7.498, de 25/7/1986 e por protocolos ministeriais, o enfermeiro é respaldado a prestar assistência, realizar consultas de enfermagem, prescrever assistência e interação com o paciente. Portanto, é capacitado para conduzir o pré-natal de baixo risco. De acordo com a Organização Mundial da Saúde (OMS) o início precoce do prénatal é essencial para adequada assistência. O número ideal de consultas seria igual ou superior a seis em uma paciente de puerpério (OMS, 2016).

Em relação ao número de gestações, $69 \%$ estavam vivenciando a experiência de ser mãe pela primeira vez, sendo que o restante vivia entre a $2^{\circ}$ e $3^{\circ}$ gestação, e $100 \%$ das entrevistadas realizaram seu atendimento pelo Sistema Único de Saúde (SUS). Neste sentido, desempenhar o papel materno, considerando todas as mudanças implicadas no nascimento, em especial do primeiro filho, faz com que a mãe entre em uma nova e única forma de organização psíquica, sendo este um momento que reaviva muitas emoções na mulher (ZANATTA e PEREIRA, 2015).

Quanto ao tipo de parto, 46\% realizaram cesariana e 54\% realizaram parto normal. Diante dos dados, observa-se uma estabilização na realização de partos por cesárea, o que pode estar vinculado ao Protocolo Clinico de Diretrizes Terapêuticas (PCDT), publicado em 2016 pelo Ministério da Saúde, trazendo parâmetros que devem ser seguidos pelos 
serviços de saúde para realização de cesariana, com objetivo de diminuir o número de procedimentos, uma vez que, quando não indicado corretamente, traz inúmeros riscos para o recém-nascido e grande risco de morte materna e infantile (BRASIL, 2016). Ao analisar os aspectos relacionados ao tipo de parto da presente pesquisa, os dados apresentados contribuem para o fortalecimento do Programa de Humanização no Prénatal e Nascimento (PHPN). Em nota publicada pelo Ministério da Saúde (MS), pela primeira vez desde 2010, o número de cesarianas na rede pública e privada de saúde não cresceu no Brasil. A curva caiu 1,5 ponto percentual em 2015. Em 2016, considerando apenas os procedimentos realizados pelo Sistema Único de Saúde (SUS), os partos normais já superam as cesarianas, acontecendo em 59,8\% dos casos. O parto normal é ativo e mais saudável por ser natural da fisiologia humana, tendo em vista que o copo da mulher foi preparado para tal, com a parturiente sendo protagonista no ato, o que não é percebido na cesariana, por ser um procedimento cirúrgico. Ressalta-se a importância do trabalho interdisciplinar durante o pré-natal, onde possa ocorrer a disponibilidade de informações sobre a gestação e parto, favorecendo a inclusão das gestantes no processo decisório, oportunizando a manifestação de sua autonomia em relação à via de parto.

Após a análise dos dados, foi possível fazer a formulação das seguintes categorias: percepções, expectativas e conhecimentos sobre o parto humanizado; contato precoce pele a pele entre mãe e filho; e comunicação como componente do cuidado durante o parto.

\section{Categoria 1: Percepções, expectativas e conhecimentos sobre o parto humanizado}

As depoentes da maternidade referiram que humanização do parto e nascimento é a realização de um parto sem nenhum tipo de manobras ou adição de drogas, como a ocitocina. Entendem, ainda, que dar atenção à parturiente e orientá-la no pré-natal é uma forma de humanizar a assistência ao parto, bem como a permanência de um acompanhante em tempo integral. Essa categoria expressa: percepções, expectativas e conhecimentos sobre o parto humanizado, fato ilustrado nos depoimentos a seguir:

[...] Parto humanizado, é ter um familiar ao meu lado na hora do parto, mas não é o que acontece, é um direito nosso, mas o hospital não deixa. [...]. P02 (US1).

[...] Acredito que o parto humanizado nos traz alivio da dor, conforto, tranquilidade, segurança na hora do nascimento do bebê, sem remédio na veia [...] P05 (US 10). 
[...] No posto durante as consultas ouvi falar que o parto humanizado traz segurança na hora de ganhar o bebê, seria bom se nós tivéssemos um acompanhante, eu sei que particular tem [...]. P06 (US8).

[...] Não tive acompanhante, por ser pelo SUS, porque o hospital não permite eu acho, era só eu e Deus [...]. P12 (US3).

Diante os discursos das mulheres, observa-se que elas reconhecem seus direitos e compreendem, em partes, o que é parto humanizado, percebendo muitas vezes seus direitos sendo violados por normas institucionais rígidas no ambiente hospitalar. A escolha do acompanhante durante o trabalho de parto, parto e pós-parto imediato, é recomendada pela Organização Mundial de Saúde (OMS), desde 1985, a partir da Conferência Sobre Tecnologia Apropriada para o Nascimento e parto. O apoio durante o processo de nascimento traz inúmeros benefícios, apontados em uma revisão sistemática publicada pela Cochrane Library por meio de 22 ensaios clínicos randomizados, avaliando o apoio ofertado pelo acompanhante de escolha da mulher durante o trabalho de parto. $\mathrm{O}$ fato resultou em aumento de partos vaginais, redução analgésica, diminuição do tempo de parto e maior satisfação da mulher com a experiência do nascimento (HODNETT et al., 2013).

O suporte contínuo durante o trabalho de parto traz benefícios clinicamente significativos para mulheres e bebês, sendo um direito legislado que todas as mulheres devem ter apoio e ser garantido pelos serviços de saúde. Segundo o Ministério da Saúde, o conceito de "assistência humanizada" é vasto e envolve um conjunto de práticas e atitudes com o objetivo de favorecer o parto e o nascimento saudável, abrangendo um conjunto de cuidados de forma integral que visam à gestante e sua família a possibilidade de parto e puerpério com privacidade e autonomia e não por meio de rotinas institucionais estabelecidas.

[...] Parto humanizado, já ouvi falar na TV que é na banheira, o parceiro pode estar junto ou a mãe, familiar que a pessoa gostaria de estar do lado. P09 (US4).

[...] Parto humanizado, visualizei alguns vídeos no Facebook, a mulher dentro da banheira e o marido com ela na hora do parto. [...] P8 (US13).

[...] Assisti pela internet alguns vídeos, não sabia o que significava parto humanizado, era vídeos de mães sendo preparadas na banheira [...] P7(US 15). 
Analisando o contexto descrito e tomando por base em curtas menções expressadas pelas participantes, a internet é um veículo de informação que pode contribuir para prática assistencial na área da saúde da mulher.

É direito de todo o cidadão receber um atendimento público de qualidade na área da saúde. Para tanto, é necessário um esforço coletivo garantindo que as políticas de saúde sejam implementadas de forma efetiva no ambiente intra-hospitalar. Diante dos achados, condutas adotadas contradizem a proposta do Programa de Humanização no Pré-natal e Nascimento (PHPN).

As gestantes expressam que a dor sentida e a intensidade são maiores do que conseguem suportar. No Brasil, muitas vezes é relatada como dor da solidão, da agressão, com práticas institucionais e dos profissionais de saúde que criam e reforçam sentimentos de incapacidade, inadequação e impotência da mulher com seu corpo, como expressam nas menções:

[...] Mandaram eu caminhar por duas horas, eles me deram uma injeção para dilatar, estava perdendo liquido com uma dor muito forte [...] P4(US 07).

[...] Fiquei das 07 horas da manhã até a noite do outro dia fazendo soro para tentar dar dilatação, e sentindo muita dor [...] P5 (US11).

[...] Trocou o plantão, entrou uma doutora fez exame de toque, iniciei soro para estimular dilatação, senti dor toda manhã, tentei não gritar, não fazer escândalo, mas por último a dor é tanto [...]. P9(US 09).

O parto humanizado compreende-se por um parto sem dor, sem sofrimento, quando potencializado por medidas que iatrogenizam, como o uso abusivo de ocitócicos, episiotomia e episiorrafia desnecessária. Estudo realizado no Brasil no ano de 2010, revelou que $25 \%$ das mulheres entrevistadas sofreram algum tipo de agressão durante a gestação e no parto com a realização de exames dolorosos e a recusa do alivio da dor (VENTURI e GODINHO, 2013). Sabe-se que a dor do parto faz parte da própria natureza humana e, ao contrário de outras experiências dolorosas agudas e crônicas, não está associada à patologia, mas sim com a experiência de gerar uma nova vida. Para tanto, algumas mulheres consideram que é a pior dor sentida e, na maioria das vezes, superior ao que esperavam. O emprego de medidas não farmacológicas pode auxiliar a parturiente no alivio da dor, tais como: a massagem terapêutica (diminui a dor), aroma terapia 
(diminui ansiedade e medo), banho de imersão, este sendo indicado seu início após $3 \mathrm{~cm}$ de dilatação para não prolongar o trabalho de parto e não prejudicar os resultados neonatais (GAYESKI e BRÜGGEMANN, 2010).

O grande desafio do controle da dor inicia-se com a mensuração, já que a dor é subjetiva e de caráter individual, variando em função de vivências culturais, emocionais e ambientais. Salienta-se a importância da educação e treinamento contínuos para modificar comportamento e práticas que vão na contramão do que é preconizado para uma assistência de qualidade, digna e que promova até mesmo a segurança da parturiente durante o parto (MAFETONI e SHIMO, 2014).

\section{Categoria 2: Contato precoce pele a pele entre mãe e filho}

As entrevistadas relatam o significado do contato pele a pele mãe-filho em discursos que abrangeram desde a naturalidade do momento até a felicidade proporcionada pelo contato, fatos evidenciados nos discursos a seguir:

[...] O melhor momento do mundo, o primeiro contato com meu bebê, a melhor parte do dia, da vida, que ele nasceu bem, que ele estava perfeito [...] P03 (USO7).

[...] Esse contato foi bom, ele estava chorando desesperado, na hora que ele encostou em mim, já parou de chorar ficou calmo. [...] P04 (US16).

[...] A pediatra primeiro atendeu ela rapidinho e depois levou para mim e deixou lá comigo, foi muito bom, mágico, melhor momento que tem. [...] P10 (US10).

[...] Colocaram em cima de mim, deixaram uns 10 minutos, depois eu que disse se eles quisessem levar para arrumar, para não correr risco ou qualquer coisa, daí eles pegaram e levaram [...] P13 (US13).

A realização do contato pele a pele precoce mãe-filho proporciona para mãe tranquilidade e segurança, este momento tão esperado ela pode sentir o seu filho, ver, segurar o seu bebê, e toda a ansiedade e curiosidade pode ser sanada. Sendo um método barato, seguro e de comprovados benefícios tanto para mãe quanto para o seu bebê (SAMPAIO, BOUSQUAT e BARROS, 2016). Em uma metanálise, esse contato contribui para amamentação e na estabilidade fisiológica do recém-nascido. Apesar das evidências favoráveis, ele é, ainda, desconhecido e negligenciado por muitos profissionais $\mathrm{A}$ percepção da mãe em relação à imagem do recém-nascido $(\mathrm{RN})$ gera 
sentimentos inesperados, quando o bebê deixa de ser idealizado e torna-se um ser real (MOORE et al., 2012).

Perante alguns relatos, podemos identificar práticas influenciadas por meio de rotinas estabelecidas no ambiente intra-hospitalar em relação ao contato pele a pele como algo mecânico, o que não permitiu às puérperas a experiência do verdadeiro contato com seu filho.

[...] Quando eu ganhei, só mostraram ele e trouxeram para a maternidade e depois de uma hora levaram para mamar, daí ele ficou comigo quatro horas na recuperação e depois foi para o quarto comigo[...] P05 (US11).

[..] Logo que nasceu eles botaram aqui e eu disse ela não está chorando, não está se mexendo, daí elas correram, umas cinco enfermeiras, chamaram a pediatra, fiquei ali sem saber de nada preocupada. P09(US15)

[...] Não tive contato com ele quando nasceu, vi depois mais tarde, ele nasceu prematuro e saíram correndo eu vi apenas ele de longe [...] P12 (US13).

Em determinadas situações, onde o contato precoce não pode ser realizado imediatamente após o parto, seja por comprometimento da vitalidade do bebê, o contato necessita ser retomado assim que apresentar condições favoráveis para acontecer o vínculo (DOS SANTOS FUCKS et al., 2015). Em algumas situações, este vínculo precisa ser adiado, quando ocorre comprometimento da saúde da mãe e/ou do bebê. Um caso isolado de prematuridade foi um fator que prejudicou o contato precoce com uma das entrevistadas nesse estudo, sendo que o prematuro nem sempre possui condições que permitam o contato maternal, pele a pele (BARBOSA, FABBRO e MACHADO, 2017).

A pouca realização do contato pele a pele em sala de parto tem reflexos negativos na promoção do aleitamento materno precoce, pois este contato cria um ambiente favorável à prática da amamentação, que proporciona uma melhor adaptação do RN à vida extrauterina, além de propiciar aumento do vinculo entre mãe e bebê (DE MELO, DAVIM e DA SILVA, 2015). Portanto, faz-se necessário dialogar sobre o assunto com os profissionais do e2local do estudo, sensibilizando-os sobre a importância deste contato e demostrando aos mesmos o quanto este momento é o precursor para inúmeros benefícios tanto para o RN, quanto para a puérpera na primeira hora de vida do bebê, 
contribuindo, desta forma, para uma assistência humanizada, acolhedora e para própria segurança e proteção do RN.

Cabe ressaltar que gestores do âmbito hospitalar e profissionais da equipe de enfermagem necessitam despertar uma visão ampla, oferecendo condições favoráveis para potencializar a Humanização por meio de um espaço físico adequado para receber a mãe, seu filho e seu acompanhante. Este deve ser um espaço de recuperação de saúde, harmonioso, saudável e sustentável (BRASIL,2017). Os serviços de saúde, bem como o ambiente hospitalar, devem implementar, de forma efetiva, estratégias estabelecidas pelo Ministério da Saúde (MS), tais como a Rede Cegonha, operacionalizada pelo Sistema Único de Saúde (SUS), fundamentada nos princípios da humanização, e assistência à mulheres, recém-nascidos e crianças, por meio de diretrizes que devem estar em consonância com a Portaria nº 4.729/GM/MS, 2010.

Outra estratégia do Ministério da Saúde (MS) que pode contribuir com serviços de saúde, de acordo com as normas de Atenção Humanizada do Recém-Nascido, é o Método Mãe Canguru (MMC), que é uma forma de assistência neonatal que consiste no contato pele a pele precoce entre mãe e o recém-nascido prematuro de baixo peso de forma crescente, permitindo uma participação maior dos pais no cuidado ao recém-nascido (GONJITO, XAVIER e FREITAS, 2012). O MMC traz inúmeros benefícios ao RN, vinculo mãe-filho: estimulação sensorial, aleitamento materno, controle da temperatura, infecção hospitalar, morbidade e permanência hospitalar, sendo um modelo de cuidado que insere a família no tratamento, com objetivo de humanizar a assistência, sendo uma intervenção eficaz voltada ao período neonatal.

\section{Categoria 3: Comunicação como componente do cuidado durante o parto.}

Compreende-se o cuidado como repleto de significados, englobando o estar próximo da pessoa cuidada, correspondendo às suas necessidades, respeitando suas particularidades e privacidade. A interação entre enfermeiro e mulher, no processo do parto e até o puerpério, necessita se fundamentar no "diálogo, sensibilidade, afetividade, no prazer de estar com o outro e na atenção do bem-estar físico, mental, social e espiritual" (REIS et al., 2015).

Os depoimentos seguintes detalham a forma da participação do enfermeiro durante o trabalho de parto. Dentre as atividades, citou-se o processo de comunicação efetivo, 
resultando em segurança e satisfação, facilitando o alcance da excelência do cuidado, do bem-estar da parturiente, respeitando-a na sua totalidade.

[...] Eu estava com dor e uma das enfermeiras ficou falando comigo para passar a dor, isso eu achei muito lindo, fui atendida muito bem [...] P06 (US10).

[...] As enfermeiras me cuidando, me auxiliando no que fosse preciso, explicando o que seria realizado o tempo inteiro [...] P07 (US13).

Percebe-se que o cuidado se encontra em pequenas ações: no momento de trocas, em mostrar-se presente, disposto a conhecer as necessidades do ser cuidado. Durante o trabalho de parto, essa relação interpessoal vista a dimensão do diálogo e da solidariedade. Possibilita pensá-la como recursos equivalentes às ações e tecnologias de cuidado no processo de parto (BIET e VATN, 2015).

\section{[...] As enfermeiras ficaram comigo, e eu dizia não me deixa aqui sozinha, elas ficaram do meu lado, elas falavam nós vamos ficar aqui, mas calma você precisa se acalmar. [...] P09 (US15).}

A dor é uma experiência vivenciada pela maioria das mulheres e o fato de ser fisiológica, não quer dizer que seja necessária sua vivência pela gestante. O alívio da dor representa uma medida de conforto para a mulher e, consequentemente, facilita o seu desempenho na evolução do parto, ajudando a configurar um cuidado humanizado. Os relatos confirmaram que o estabelecimento da empatia entre os profissionais e a gestante promove uma melhor percepção dos sintomas e sinais apresentados, além de compreensão das reações apresentadas pelas gestantes (FRANKLIN e BITTAR 2015). A equipe de saúde, especialmente os profissionais da enfermagem, devem estar atentas às necessidades de cada mulher de ser ouvida com a devida atenção, considerando suas queixas e demandas no período entre parto e pós-parto. A experiência da parturição para a mulher é caracterizada pelo sentimento do medo, não apenas pelo risco e sofrimento físico que julga estar exposta no parto, mas também pelo receio de não encontrar acolhida dos profissionais que a assistirão (MONTEIRO, PINHEIRO e ALVES E SOUZA, 2007).

Os resultados encontrados nesse estudo revelam que, mesmo diante de algumas normas institucionais preconizadas, as mulheres se sentiam seguras e acolhidas principalmente pela equipe de enfermagem, conforme as menções. 
[...] Tudo bom, perfeito, um bom atendimento, deu certo, ele nasceu bem, eu estou bem, está tudo ótimo [...]. P03(US 21).

[...] Enfermeiras atenciosas eu estava bem apavorada, tentavam me acalmar, me explicavam que era assim mesmo, me ensinaram a respirar para aliviar a dor, carinhosas [...]. P09(US 23).

[...] Elas são bem atenciosas, elas recebem bem, explicam como vai ser o procedimento, depois quando fui para o quarto também explicam, ajudam na amamentação, massagem na barriga por causa da cesárea. [...]. P11(US 19).

[...] Me atenderam super bem, toda hora as enfermeiras do meu lado me dando força, sendo que ali no bloco não pode ficar ninguém, a gente fica nervosa, mas deu tudo certo, elas me ajudaram em tudo até amamentar [...]. P12(US 22).

Assim, neste estudo, os dados revelam que o cuidado não representa apenas a assistência ao parto e aos eventos involutivos do puerpério, mas a assistência deve ser mais ampla, envolvendo a atenção aos aspectos subjetivos maternos, o que deve apontar para além da dimensão obstétrica. $\mathrm{O}$ fato das puérperas terem suas dúvidas esclarecidas pelos profissionais que lhe assistem durante a internação, também é percebido como uma forma de ajuda e que se constitui em elemento qualificador da assistência e de reelaboração de sua representação acerca da hospitalização (DOS SANTOS FUCKS et al., 2015)

\section{CONCLUSÃO}

Diante da realização deste estudo, observa-se que a temática "parto humanizado" vem sendo discutida e abordada durante as consultas de pré-natal, mas esse direito ainda é violado no ambiente intra-hospitalar. A não permanência de um acompanhante, por exemplo, já contradiz o que é preconizado na assistência humanizada durante o parto. $\mathrm{O}$ parto humanizado auxilia na assistência ao parto, respeitando a fisiologia da mulher, oferecendo suporte emocional para ela e possibilitando a participação de um acompanhante de sua escolha. $\mathrm{O}$ acompanhante traz tranquilidade e segurança para a mulher, deixando-a menos apreensiva, contribuindo para tornar o parto uma experiência mais agradável, proporcionando conforto, pois, neste momento, a mulher se sente com medo, insegura, fragilizada. $\mathrm{O}$ momento do trabalho de parto e o parto precisam ser vivenciados pela mulher com tranquilidade. Por isso, tendo ao seu lado um acompanhante de sua escolha, ajuda-a relaxar e contribui para um serviço humanizado. 
O contato pele a pele é essencial que ocorra imediatamente após o nascimento, pois a pele recebe estímulos sensoriais. Este contato fortalece e estimula o vínculo afetivo entre mãe-bebê. Cabe à equipe de saúde proporcionar à mãe este contato pele a pele, o aconchego, o toque, o olhar e o aleitamento materno ainda na sala de parto, propiciando à mulher a oportunidade de ver, tocar, pegar seu bebê, suprindo a expectativa que ocorreu durante a gestação e fortalecendo o vínculo mãe-bebê. Este estudo apresenta, como contribuição principal, o confronto do discurso vigente nos Programas de Saúde com a prática que o profissional institui no exercício de sua profissão. Esta estratégia possibilitará a análise do reflexo da questão da humanização do parto e nascimento, norteado pelas Políticas Públicas de Saúde, que estão sendo preconizadas no ambiente hospitalar 


\section{REFERÊNCIAS}

ANDRADE, Raquel Dully et al. Fatores relacionados à saúde da mulher no puerpério e repercussões na saúde da criança. Escola Anna Nery, v. 19, p. 181-186, 2015.

BARBOSA, Luara De Carvalho; FABBRO, Márcia Regina Cangiani; MACHADO, Geovânia Pereira dos Reis. Violência obstétrica: revisão integrativa de pesquisas qualitativas. Avances en Enfermería, 2017.

BIET, Delmary Borges; PIRES, VATN. Assistência humanizada da equipe de enfermagem no transcurso do parto: o olhar das puérperas. Revista Enfermagem Integrada-Ipatinga: Unileste, v. 8, 2015.

BRASIL. Conselho Nacional de Saúde. Resolução no 466 de 12 de Dezembro de 2012. [Acesso em: 10 de novembro de 2017]. Disponível em: http://bvsms.saude.gov.br/bvs/saudelegis/cns/2013/res0466_12_12_2012.html.

BRASIL. Ministério da Saúde. Diretriz Nacional de Assistência ao Parto Normal relatoria de recomendação. Janeiro, 2016. [Acesso em: 10 de novembro de 2017.] Disponível em: http://conitec.gov.br/images/Consultas/2016/Relatorio_Diretriz-PartoNormal_CP.pdf.

CRESWELL, John W.; CLARK, Vicki L. Plano. Pesquisa de Métodos Mistos-: Série Métodos de Pesquisa. Penso Editora, 2015.

DE MELO, Jácia Kaline Ferreira; DAVIM, Rejane Marie Barbosa; DA SILVA, Richardson Rosendo Algusto. Vantagens e desvantagens do parto normal e cesariano: opinião de puérperas. Revista de Pesquisa Cuidado é Fundamental Online, v. 7, n. 4, p. 3197-3205, 2015.

DOS SANTOS FUCKS, Ingrid et al. A sala de parto: o contato pele a pele e as ações para o estímulo ao vínculo entre mãe-bebê. Avances en Enfermería, v. 33, n. 1, p. 29-37, 2015.

FRANKLIN, Joyce Silveira; BITTAR, Cléria Maria. A HUMANIZAÇÃO DO PARTO. RELATOS DE PUÉRPERAS E PROFISSIONAIS DE UM CENTRO OBSTÉTRICO DE UM HOSPITAL PRIVADO EM UM MUNICÍPIO DE FRANCA. INVESTIGAÇÃO, v. 14, n. 2, 2015.

GAYESKI, Michele Edianez; BRÜGGEMANN, Odaléa Maria. Métodos não farmacológicos para alívio da dor no trabalho de parto: uma revisão sistemática. Texto \& Contexto-Enfermagem, v. 19, n. 4, p. 774-782, 2010.

GONÇALVES, Mariana Itamaro et al. Comunicação e segurança do paciente na passagem de plantão em unidades de cuidados intensivos neonatais. Texto \& ContextoEnfermagem, v. 25, 2016.

GONTIJO, Tarcisio Laerte; XAVIER, César Coelho; FREITAS, Maria Imaculada de Fátima. Avaliação da implantação do Método Canguru por gestores, profissionais e mães de recém-nascidos. Cadernos de Saúde Pública, v. 28, p. 935-944, 2012. 
HODNETT, Ellen D. et al. Continuous support for women during childbirth. Cochrane database of systematic reviews, n. 7, 2013.

LACERDA, Maria Ribeiro; COSTENARO, Regina Gema Santini. Metodologias da pesquisa para a enfermagem e saúde: da teoria a prática. Porto Alegre: Moriá, 2015.

MAFETONI, Reginaldo Roque; SHIMO, Antonieta Keiko Kakuda. Métodos não farmacológicos para alívio da dor no trabalho de parto: revisão integrativa. Revista Mineira de Enfermagem, v. 18, n. 2, p. 505-520, 2014.

MARQUES, Daniela Karina Antão et al. Percepções de puérperas frente à assistência de enfermagem no alojamento conjunto. Revista de Ciências da Saúde Nova Esperança, v. 12, n. 1, p. 47-59, 2014.

MINAYO, Maria Cecília de Souza et al. O desafio do conhecimento-pesquisa qualitativa em saúde. In: $O$ desafio do conhecimento-pesquisa qualitativa em saude. 2000. p. 269269.

MONTEIRO, Maria Adelane Alves; PINHEIRO, Ana Karina Bezerra; ALVES E SOUZA, Ângela Maria. Vivência de puérperas com filhos recém-nascidos hospitalizados. Escola Anna Nery, v. 11, p. 276-282, 2007.

MOORE, Elizabeth R. et al. Early skin-to-skin contact for mothers and their healthy newborn infants. Cochrane database of systematic Reviews, n. 11, 2016.

OMS. Organização Mundial da Saúde. Recomendações da OMS sobre cuidados prénatais para uma experiência positiva na gravidez. [Acesso em: 12 de novembro de 2017.] Disponível em: http://apps.who.int/iris/bitstream/10665/250800/2/WHO-RHR-16.12por.pdf

PINHEIRO, Bruna Cardoso; BITTAR, Cléria Maria Lobo. Percepções, expectativas e conhecimentos sobre o parto normal: relatos de experiência de parturientes e dos profissionais de saúde. Aletheia, n. 37, p. 212-227, 2012.

REIS, Thamiza da Rosa dos et al. Enfermagem obstétrica: contribuições às metas dos Objetivos de Desenvolvimento do Milênio. Revista Gaúcha de Enfermagem, v. 36, p. 94-101, 2015.

RODRIGUES, Dafne Paiva et al. Cuidados ao binômio mãe-filho no puerpério imediato: estudo descritivo. Online Brazilian Journal of Nursing, v. 13, n. 2, p. 227-238, 2014.

SAMPAIO, Ádila Roberta Rocha; BOUSQUAT, Aylene; BARROS, Claudia. Contato pele a pele ao nascer: um desafio para a promoção do aleitamento materno em maternidade pública no Nordeste brasileiro com o título de Hospital Amigo da Criança. Epidemiologia e Serviços de Saúde, v. 25, p. 281-290, 2016.

TRIVIÑOS, Augusto Nibaldo Silva. Introdução à pesquisa em ciências sociais: a pesquisa qualitativa em educação. São Paulo: Atlas, 1987. Outros números do Informe Rural ETENE: ANO, v. 3, p. 25, 2009. 
VENTURI, Gustavo; GODINHO, Tatau. Mulheres brasileiras e gênero nos espaços público e privado: uma década de mudanças na opinião pública. In: Mulheres brasileiras e gênero nos espaços público e privado: uma década de mudanças na opinião pública. 2013.

ZANATTA, Edinara; PEREIRA, Caroline Rubin Rossato. "Ela enxerga em ti o mundo": A experiência da maternidade pela primeira vez. Temas em Psicologia, v. 23, n. 4, p. 959-972, 2015.

Recebido em: 01/12/2021

Aprovado em: 23/12/2021

Publicado em: 28/12/2021 